\title{
Hypothesis Testing for the Questionnaire Investigation on the Needs and Images at Fuji City in Shizuoka Prefecture
}

\author{
Daisuke Suzuki ${ }^{1}$, Akane Okubo $^{2}$, Yuki Higuchi ${ }^{3} \&$ Kazuhiro Takeyasu ${ }^{4}$ \\ ${ }^{1}$ Fujisan Area Management Company, Japan \\ ${ }^{2}$ Nihon University Junior College, Japan \\ ${ }^{3}$ Faculty of Business Administration, Setsunan University, Japan \\ ${ }^{4}$ College of Business Administration, Tokoha University, Japan \\ Correspondence: Kazuhiro Takeyasu, College of Business Administration, Tokoha University, Japan.
}

Received: April 16, 2018

doi:10.5430/ijba.v9n3p18
Accepted: May 6, 2018

Online Published: May 10, 2018

URL: https://doi.org/10.5430/ijba.v9n3p18

\begin{abstract}
Shopping streets at local city in Japan became old and are generally declining. In this paper, we handle the area rebirth and/or regional revitalization of shopping street. We focus on Fuji city in Japan. Four big festivals are held at Fuji city (two for Fuji district and two for Yoshiwara district). Many people visit these festivals including residents in that area. Therefore a questionnaire investigation to the residents and visitors is conducted during these periods in order to clarify residents and visitors' needs for the shopping street, and utilize them to the plan building of the area rebirth and/or regional revitalization of shopping street. Hypothesis testing was executed based on that. There is a big difference between Fuji district and Yoshiwara district. Therefore we focus Yoshiwara district in this paper. We have set 9 Null hypotheses. In the hypothesis testing, 3 cases out of 9 null hypotheses were rejected and 1/3 of hypotheses were insisted clearly. We have obtained fruitful results. To confirm the findings by utilizing the new consecutive visiting records would be the future works to be investigated.
\end{abstract}

Keywords: Fuji city, area rebirth, regional vitalization, festival, hypothesis testing

\section{Introduction}

Shopping streets at local city in Japan are generally declining. It is because most of them were built in the so-called "High Growth Period (1954-1973)". Therefore they became old and area rebirth and/or regional revitalization are required everywhere.

There are many papers published concerning area rebirth or regional revitalization. Inoue (2017) has pointed out the importance of tourism promotion. Ingu et al. (2017) made a study on the application of geothermal power generation to local revitalization in Obama Town. Kotani (2017) developed the project of shutter art to Wakkanai Chuo shopping street in Hokkaido, Japan. Ohkubo (2017) has made a questionnaire research at Jigenji shopping street in Kagoshima Prefecture, Japan and analyzed the current condition and future issues. For about tourism, many papers are presented from many aspects as follows.

Yoshida et al. (2009) designed and conducted a visitor survey on the spot, which used a questionnaire to investigate the activities of visitors to the Ueno district in Taito ward, Tokyo. Doi et al. (2009) analyzed the image of the Izu Peninsula as a tourist destination in their 2003 study "Questionnaire Survey on the Izu Peninsula." Kano (2011) conducted tourist behavior studies in Atami city in 2008, 2009, 2014 and in other years.

In this paper, we handle the area rebirth and/or regional revitalization of shopping street. We focus on Fuji city in Japan. Fuji city is located in Shizuoka Prefecture. Mt. Fuji is very famous all around the world and we can see its beautiful scenery from Fuji city, which is at the foot of Mt. Fuji. There are two big shopping street in Fuji city. One is Yoshiwara shopping street and another one is Fuji shopping street. They became old and building area rebirth and regional revitalization plan have started. Following investigation was conducted by the joint research group (Fuji Chamber of Commerce \& Industry, Fujisan Area Management Company, Katsumata Maruyama Architects, Kougakuin University and Tokoha University). The main project activities are as follows.

A. Investigation on the assets which are not in active use 
B. Questionnaire Investigation to Entrepreneur

C. Questionnaire Investigation to the residents and visitors

After that, area rebirth and regional revitalization plan were built.

In this paper, we handle above stated $\mathrm{C}$.

Four big festivals are held at Fuji city. Two big festivals are held at Yoshiwara district(Yoshiwara shopping street) and two big festivals at Fuji district(Fuji shopping street).

At Yoshiwara district, Yoshiwara Gion Festival is carried out during June and Yoshiwara Shukuba (post-town) Festival is held during October. On the other hand, Kinoene Summer Festival is conducted during August and Kinoene Autumn Festival is performed during October at Fuji district. Many people visit these festivals including residents in that area.

Therefore questionnaire investigation of $\mathrm{C}$ is conducted during these periods.

Finally, we have obtained 982 sheets (Yoshiwara district: 448, Fuji district: 534).

Basic statistical analysis and Bayesian Network analysis are executed based on that.

In this paper, a questionnaire investigation is executed in order to clarify residents and visitors' needs for the shopping street, and utilize them to the plan building of the area rebirth and/or regional revitalization of shopping street. Hypothesis testing was executed based on that. There is a big difference between Fuji district and Yoshiwara district. Therefore we focus Yoshiwara district in this paper. Another one will be discussed in another paper. We have set 9 Null hypotheses. Some interesting and instructive results are obtained.

The rest of the paper is organized as follows. Outline of questionnaire investigation is stated in section 2. In section 3, Hypothesis testing is executed which is followed by the Remarks is stated in section 4 .

\section{Outline and the Basic Statistical Results of the Questionnaire Research}

\subsection{Outline of the Questionnaire Research}

A questionnaire investigation to the residents and visitors is conducted during these periods in order to clarify residents and visitors' needs for the shopping street, and utilize them to the plan building of the area rebirth and/or regional revitalization of shopping street. The outline of questionnaire research is as follows. Questionnaire sheet is attached in Appendix 1.

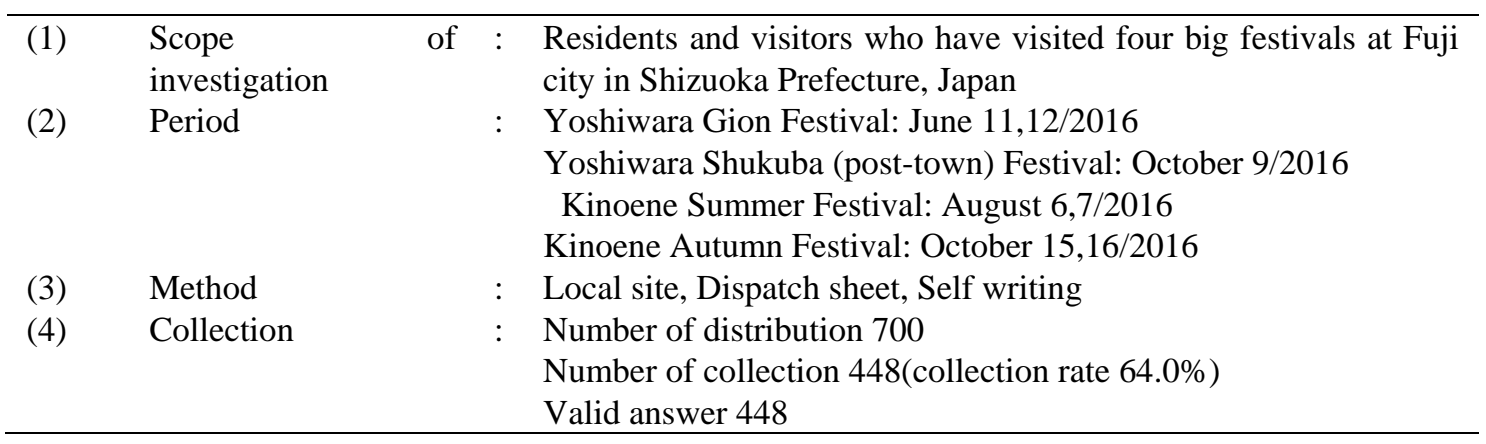

\subsection{Basic Statistical Results}

Now, we show the main summary results by single variable.

\subsubsection{Characteristics of Answers}

(1) Sex (Q7)

Male $55.6 \%$, Female $44.4 \%$

These are exhibited in Figure 1. 


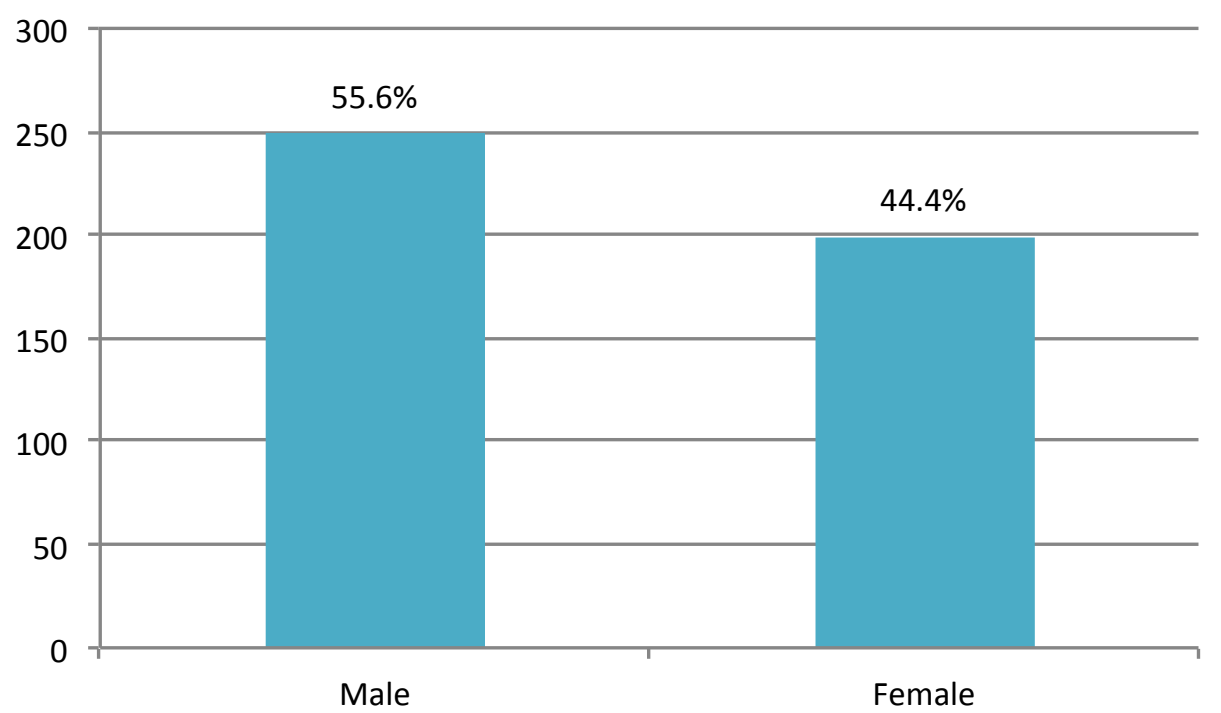

Figure 1. Sex (Q7)

(2) Age (Q8)

$10^{\text {th }} 10.9 \%, 20^{\text {th }} 12.1 \%, 30^{\text {th }} 19.0 \%, 40^{\text {th }} 17.9 \%, 50^{\text {th }} 13.4 \%, 60^{\text {th }} 14.7 \%$, More than $7011.6 \%$

These are exhibited in Figure 2.

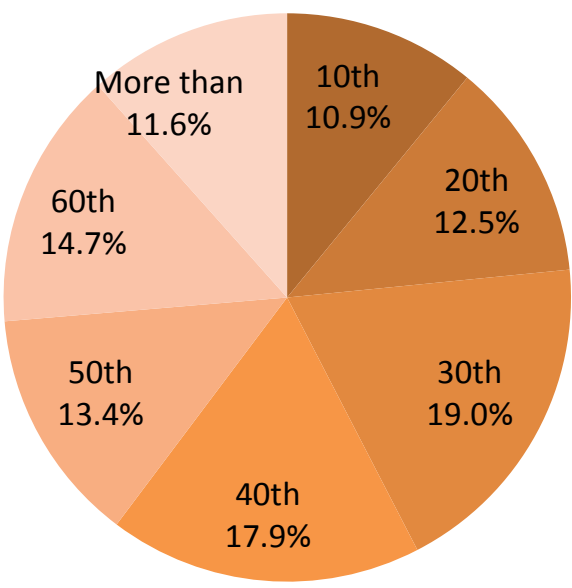

Figure 2. Age (Q8)

(3) Residence (Q9)

a. Fuji city $78.3 \%$, b. Fujinomiya city $6.9 \%$, c. Numazu city $4.5 \%$, d. Mishima city $1.3 \%$, e. Shizuoka city $2.9 \%$, F. Else (in Shizuoka Prefecture) 2.5\%, g. Outside of Shizuoka Prefecture 3.6\%

These are exhibited in Figure 3. 


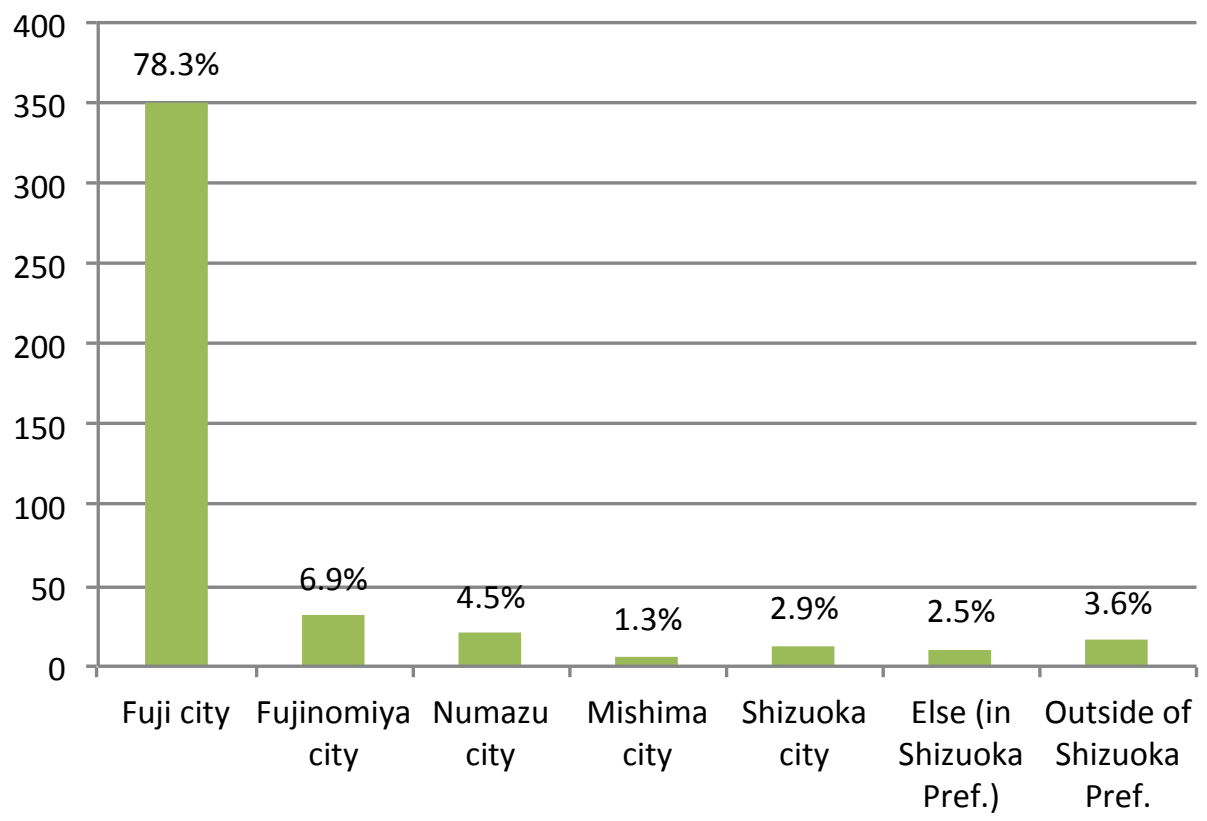

Figure 3. Residence (Q9)

2.2.2 Summary Results for the Items Used in Hypothesis Testing

(1) How often do you come to this shopping street? (Q1)

Everyday $12.9 \%$, More than 1 time a week $15.6 \%$, More than 1 time a month $23.4 \%$,

More than 1 time a year $37.3 \%$, First time $5.1 \%$, Not filled in $5.6 \%$

These are exhibited in Figure 4.

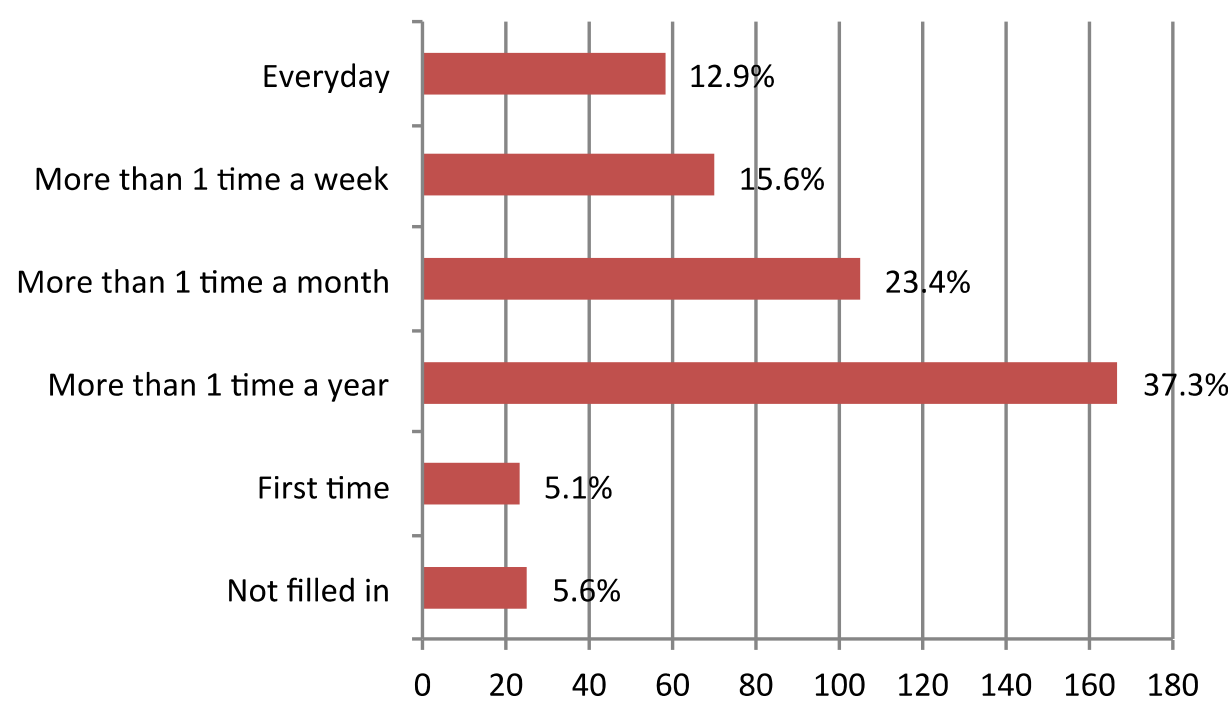

Figure 4. How often do you come to this shopping street? (Q1)

(2) What is the purpose of visiting here? (Q2)

Shopping $20.7 \%$, Eating and drinking $13.1 \%$, Business $7.5 \%$, Celebration, event $47.5 \%$, 
Leisure, amusement 1.5\%, miscellaneous 9.7\%

These are exhibited in Figure 5.

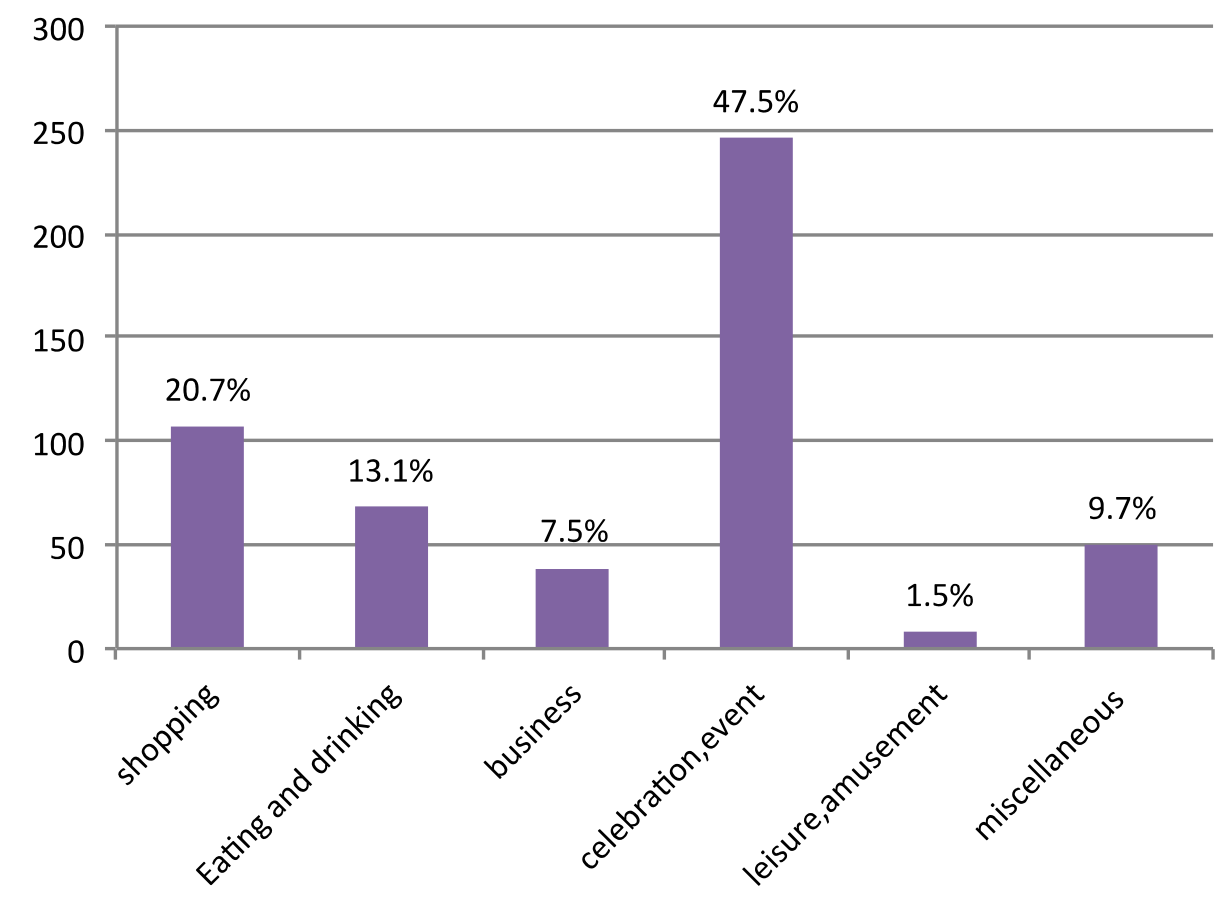

Figure 5. What is the purpose of visiting here? (Q2)

(3) How do you feel about the image of the surrounding area at this shopping street? (Q3)

Beautiful $51.9 \%$, Ugly $48.1 \%$, Of the united feeling there is $47.2 \%$, Scattered $52.8 \%$,

Varied $40.0 \%$,Featureless $60.0 \%$, New $32.5 \%$,Historic $67.5 \%$, Full of nature $53.1 \%$,Urban $46.9 \%$,

Cheerful 49.4\%, Gloomy 50.6\%, Individualistic $46.3 \%$, Conventional $53.7 \%$, Friendly $61.6 \%$,

Unfriendly $38.4 \%$, Healed $54.2 \%$, Stimulated $45.8 \%$, Open $47.9 \%$, exclusive $52.1 \%$, Want to reside $45.1 \%$,

Do not want to reside $54.9 \%$, Warm $62.6 \%$, Aloof $37.4 \%$, Fascinating $49.6 \%$, Not fascinating $50.4 \%$,

Want to play $47.8 \%$, Want to examine deliberately $52.2 \%$, Lively $40.3 \%$, Calm $59.7 \%$,

Atmosphere of urban $30.5 \%$, Atmosphere of rural area $69.5 \%$

These are exhibited in Figure 6. 


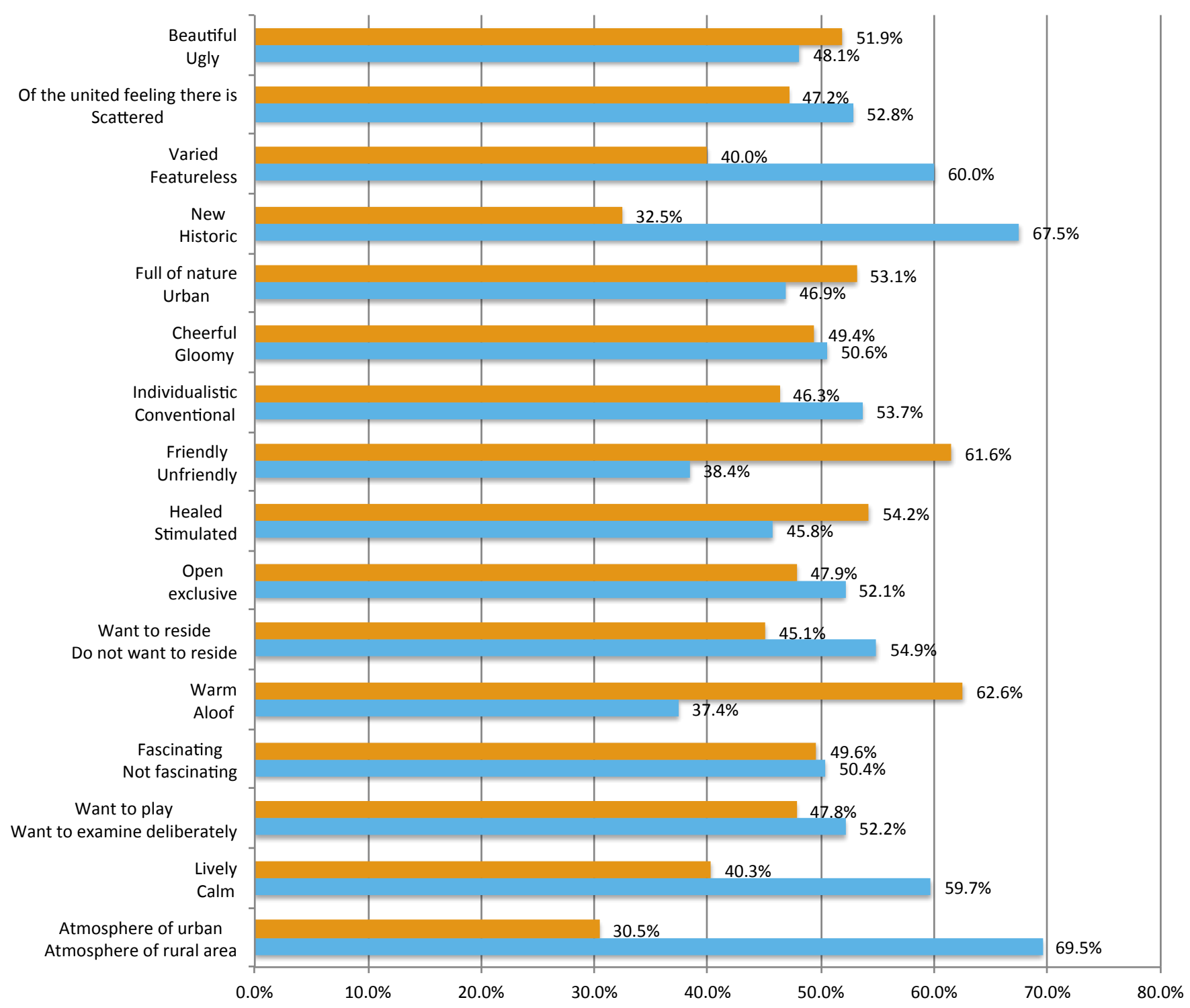

Figure 6. How do you feel about the image of the surrounding area at this shopping street? (Q3)

(4) There are many old building at the age of nearly 50 years. Do you think we can still use them? (Q4)

Can use it $38.6 \%$, Cannot use it $33.9 \%$, Have no idea $27.5 \%$

These are exhibited in Figure 7. 


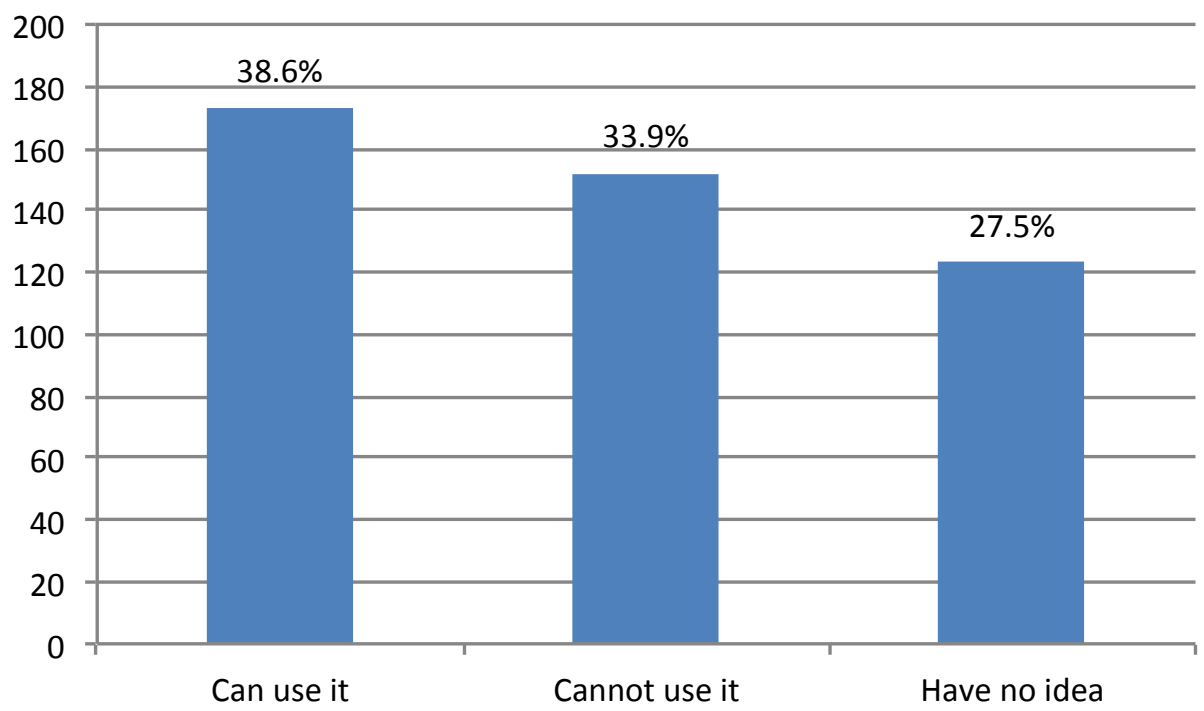

Figure 7. There are many old building at the age of nearly 50 years. Do you think we can still use them? (Q4)

\section{Hypothesis Testing}

Hereinafter we make hypothesis testing based upon the questionnaire investigation data.

\subsection{Setting Hypothesis}

We set the following 9 themes before setting Null Hypothesis.

A-1) Those who come frequently (every day) think that old buildings cannot be used.

A-2) Those who do not come so often (once a year) think that old buildings cannot be used.

A-3) Those who are at the age of less than 40 think that old buildings can be used.

A-4) Women think that old buildings cannot be used.

A-5) Those who answered that old buildings can be used think that they want to reside.

A-6) Those who answered that the image of the street is lively think that they want to reside.

A-7) Those who came from far away (Miscellaneous in Shizuoka Prefecture, Outside of Shizuoka Prefecture) think that they cannot judge whether old buildings can be used or not.

A-8) Those who answered that the purpose of visiting the shopping street is eating and drinking are male in majority.

A-9) Those who live in Fuji city have the purpose of eating and drinking while visiting the shopping street.

Now, we set the following 9 Null hypotheses.

B-1) There is not so much difference whether "those who come frequently (every day) think that old buildings cannot be used" or not.

B-2) There is not so much difference whether "those who do not come so often (once a year) think that old buildings cannot be used" or not.

B-3) There is not so much difference whether "those who are at the age of less than 40 think that old buildings can be used" or not.

B-4) There is not so much difference whether "women think that old buildings cannot be used" or not.

B-5) There is not so much difference whether "those who answered that old buildings can be used think that they want to reside" or not.

B-6) There is not so much difference whether "those who answered that the image of the street is lively think that they want to reside" or not.

B-7) There is not so much difference whether "those who came from far away ( Miscellaneous in Shizuoka Prefecture, Outside of Shizuoka Prefecture) think that they cannot judge whether old buildings can be used or not" or 
not.

B-8) There is not so much difference whether " $t$ hose who answered that the purpose of visiting the shopping street is eating and drinking are male in majority" or not.

B-9) There is not so much difference whether "those who live in Fuji city have the purpose of eating and drinking while visiting the shopping street" or not.

\subsection{Hypothesis Testing}

$x^{2}$ hypothesis testing is executed in order to clarify tourists' behavior. $x^{2}$ hypothesis testing is to clarify the difference between the expected value and the observed data, which is shown in Eq.(1).

$$
x^{2}=\sum_{i=1}^{n} \frac{\left(O_{i}-E_{i}\right)^{2}}{E_{i}}
$$

Where $O_{i}$ is an observed data and $E_{i}$ is an expected value. The results of statistical hypothesis testing are as follows.

Null Hypothesis B-1) There is not so much difference whether "those who come frequently (every day) think that old buildings cannot be used" or not.

Summary table concerning Null Hypothesis B-1) is exhibited in Table 1.

Table 1. Summary table for Null Hypothesis B-1)

Q1: How often do you come to this shopping street? Everyday

Q4: There are many old building at the age of nearly 50 years. Do you think we can still use them?

\begin{tabular}{llllll}
\hline & & & \multicolumn{2}{c}{ Q4 } & Total \\
\hline Q1 & Everyday & Frequency & 25 & 33 & 58 \\
& & $\%$ & 43.10 & 56.90 & 100.00 \\
& Less than that & Cannot use it /Have no idea & 365 \\
\multirow{4}{*}{ Total } & & $\%$ & 38.36 & 61.64 & 100.00 \\
& & Frequency & 165 & 258 & 423 \\
& & $\%$ & 39.01 & 60.99 & 100.00 \\
\hline
\end{tabular}

Significance probability 0.491

The null hypothesis is not rejected. It can be said that there is not so much difference whether "those who come frequently (every day) think that old buildings cannot be used" or not.

Null Hypothesis B-2): There is not so much difference whether "those who do not come so often (once a year) think that old buildings cannot be used" or not.

Summary table concerning Null Hypothesis B-2) is exhibited in Table 2.

Table 2. Summary table for Null Hypothesis B-2)

Q1: How often do you come to this shopping street? 1 time a year

Q4: There are many old building at the age of nearly 50 years. Do you think we can still use them?

\begin{tabular}{llllll}
\hline & & & \multicolumn{2}{c}{ Q4 } & Total \\
\hline Q1 & 1 time a year & Frequency & 73 & 94 & 167 \\
& & $\%$ & 43.71 & 56.29 & 100.00 \\
& More than & Frequency & 92 & 164 & 256 \\
\multirow{2}{*}{ Total } & that & $\%$ & 35.94 & 64.06 & 100.00 \\
& & Frequency & 165 & 258 & 423 \\
& & $\%$ & 39.01 & 60.99 & 100.00 \\
\hline
\end{tabular}

Significance probability 0.109 
The null hypothesis is not rejected. It can be said that there is not so much difference whether "those who do not come so often (once a year) think that old buildings cannot be used" or not.

Null Hypothesis B-3) There is not so much difference whether "those who are at the age of less than 40 think that old buildings can be used" or not.

Summary table concerning Null Hypothesis B-3) is exhibited in Table 3.

Table 3. Summary table for Null Hypothesis B-3)

Q8: Age

Q4: There are many old building at the age of nearly 50 years. Do you think we can still use them?

\begin{tabular}{llllll}
\hline & & & \multicolumn{2}{c}{ Q4 } \\
& & Can use it & Cannot use it /Have no idea & Total \\
\hline Q8 & Less than & Frequency & 106 & 164 & 270 \\
& 40th & $\%$ & 39.26 & 60.74 & 100.00 \\
& More than & Frequency & 67 & 111 & 178 \\
& 50 th & $\%$ & 37.64 & 62.36 & 100.00 \\
Total & & Frequency & 173 & 275 & 448 \\
& & $\%$ & 38.62 & 61.38 & 100.00 \\
\hline
\end{tabular}

\section{Significance probability 0.731}

The null hypothesis is not rejected. It can be said that there is not so much difference whether "those who are at the age of less than 40 think that old buildings can be used" or not.

Null Hypothesis B-4) There is not so much difference whether "women think that old buildings cannot be used" or not.

Summary table concerning Null Hypothesis B-4) is exhibited in Table 4.

Table 4. Summary table for Null Hypothesis B-4)

Q7: Sex

Q4: There are many old building at the age of nearly 50 years. Do you think we can still use them?

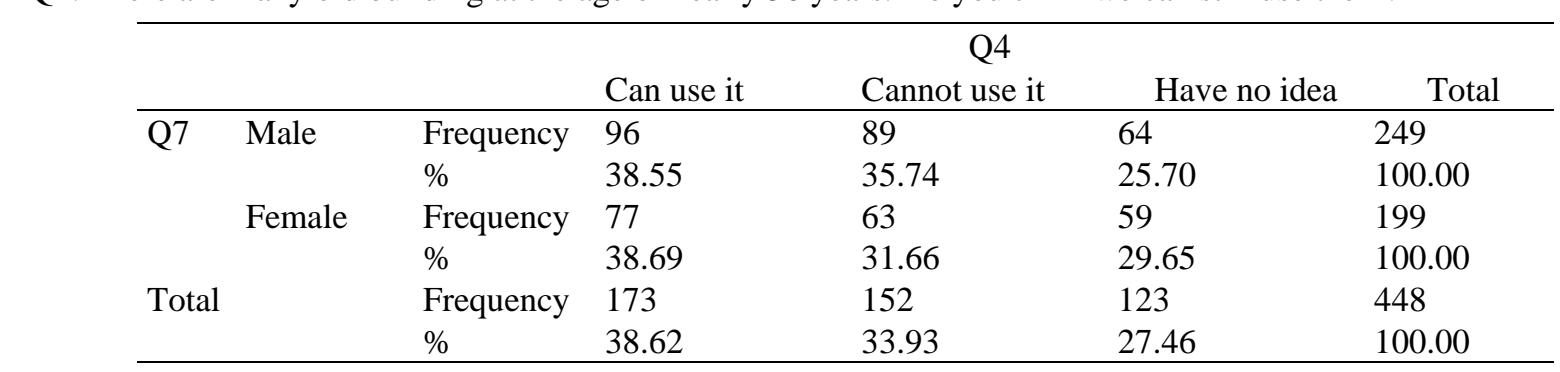

Significance probability 0.976

The null hypothesis is not rejected. It can be said that there is not so much difference whether "women think that old buildings cannot be used" or not.

Null Hypothesis B-5) There is not so much difference whether "those who answered that old buildings can be used think that they want to reside" or not.

Summary table concerning Null Hypothesis B-5) is exhibited in Table 5. 
Table 5. Summary table for Null Hypothesis B-5)

Q4: There are many old building at the age of nearly 50 years. Do you think we can still use them?

Q3: How do you feel about the image of the surrounding area at this shopping street? : Want to reside

\begin{tabular}{llllll}
\hline & & \multicolumn{3}{c}{ Q3: Want to reside } \\
& & & Think so/ Not specified & Do not think so & Total \\
\hline Q4 & Can use it & Frequency & 116 & 57 & 173 \\
& & $\%$ & 67.05 & 32.95 & 100.00 \\
& Cannot use it /Have & Frequency & 157 & 118 & 275 \\
\multirow{2}{*}{ Total } & no idea & $\%$ & 57.09 & 42.90 & 100.00 \\
& & Frequency & 273 & 175 & 448 \\
& & $\%$ & 60.94 & 39.06 & 100.00 \\
\hline
\end{tabular}

Significance probability 0.035

The null hypothesis is rejected with $4 \%$ significance level. It can be said that those who answered that old buildings can be used think that they want to reside.

Null Hypothesis B-6) There is not so much difference whether "those who come frequently (every day) think that old buildings cannot be used" or not.

Summary table concerning Null Hypothesis B-6) is exhibited in Table 6.

Table 6. Summary table for Null Hypothesis B-6)

Q3: How do you feel about the image of the surrounding area at this shopping street? : Lively

Q3: How do you feel about the image of the surrounding area at this shopping street? : Want to reside

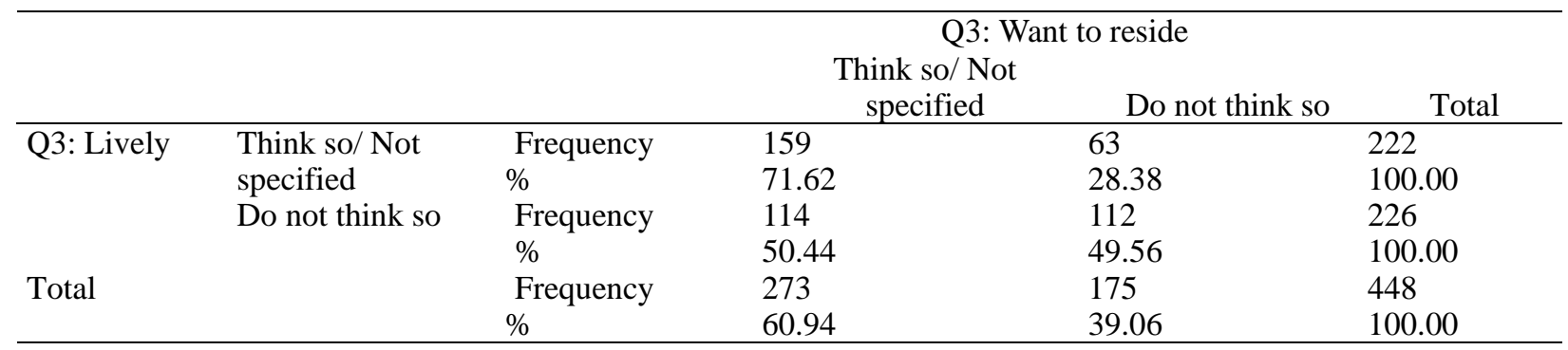

Significance probability 0.000

The null hypothesis is rejected with $1 \%$ significance level. It can be said that those who answered that the image of the street is lively think that they want to reside.

Null Hypothesis B-7) There is not so much difference whether "those who came from far away (Miscellaneous in Shizuoka Prefecture, Outside of Shizuoka Prefecture) think that they cannot judge whether old buildings can be used or not" or not.

Summary table concerning Null Hypothesis B-7) is exhibited in Table 7.

Table 7. Summary table for Null Hypothesis B-7)

Q9: Residence

Q4: There are many old building at the age of nearly 50 years. Do you think we can still use them?

\begin{tabular}{llllll}
\hline & & & \multicolumn{2}{c}{ Q4 } \\
& & & Can use it & \multicolumn{1}{c}{ Cannot use it/Have no idea } & Total \\
\hline Q9 & Neighborhood & Frequency & 161 & 260 & 421 \\
& & $\%$ & 38.24 & 61.76 & 100.00 \\
& Far away & Frequency & 12 & 15 & 27 \\
Total & & $\%$ & 44.44 & 55.56 & 100.00 \\
& & Frequency & 173 & 275 & 448 \\
& & $\%$ & 38.62 & 61.38 & 100.00 \\
\hline
\end{tabular}

Significance probability 0.521 
The null hypothesis is not rejected. It can be said that there is not so much difference whether "those who came from far away (Miscellaneous in Shizuoka Prefecture, Outside of Shizuoka Prefecture) think that they cannot judge whether old buildings can be used or not" or not.

Null Hypothesis B-8) There is not so much difference whether "t hose who answered that the purpose of visiting the shopping street is eating and drinking are male in majority" or not.

Summary table concerning Null Hypothesis B-8) is exhibited in Table 8.

Table 8. Summary table for Null Hypothesis B-8)

Q7: Sex

Q2: What is the purpose of visiting here? : Eating and drinking

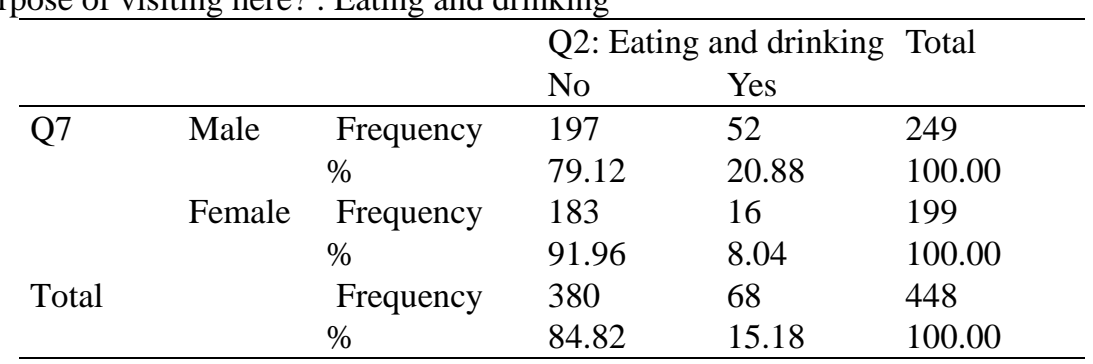

Significance probability 0.000

The null hypothesis is rejected with $1 \%$ significance level. It can be said that those who answered that the purpose of visiting the shopping street is eating and drinking are male in majority.

Null Hypothesis B-9) There is not so much difference whether "those who live in Fuji city have the purpose of eating and drinking while visiting the shopping street" or not.

Summary table concerning Null Hypothesis B-9) is exhibited in Table 9.

Table 9. Summary table for Null Hypothesis B-9)

Q9: Residence

Q2: What is the purpose of visiting here? : Eating and drinking

\begin{tabular}{|c|c|c|c|c|c|}
\hline & & \multicolumn{4}{|c|}{ Q2: Eating and drinking } \\
\hline & & & No & Yes & Total \\
\hline \multirow[t]{4}{*}{ Q9 } & Fuji city & Frequency & 293 & 58 & 351 \\
\hline & & $\%$ & 83.48 & 16.52 & 100.00 \\
\hline & Else & Frequency & 87 & 10 & 97 \\
\hline & & $\%$ & 89.69 & 10.31 & 100.00 \\
\hline \multirow[t]{2}{*}{ Total } & & Frequency & 380 & 68 & 448 \\
\hline & & $\%$ & 84.82 & 15.18 & 100.00 \\
\hline
\end{tabular}

Significance probability 0.131

The null hypothesis is not rejected. It can be said that there is not so much difference whether "those who live in Fuji city have the purpose of eating and drinking while visiting the shopping street" or not.

\section{Remarks}

The Results for Hypothesis Testing are as follows.

We set the following 7 themes.

A-1) Those who come frequently (every day) think that old buildings cannot be used.

A-2) Those who do not come so often (once a year) think that old buildings cannot be used.

A-3) Those who are at the age of less than 40 think that old buildings can be used.

A-4) Women think that old buildings cannot be used. 
A-5) Those who answered that old buildings can be used think that they want to reside.

A-6) Those who answered that the image of the street is lively think that they want to reside.

A-7) Those who came from far away (Miscellaneous in Shizuoka Prefecture, Outside of Shizuoka Prefecture) think that they cannot judge whether old buildings can be used or not.

A-8) Those who answered that the purpose of visiting the shopping street is eating and drinking are male in majority.

A-9) Those who live in Fuji city have the purpose of eating and drinking while visiting the shopping street. 3 cases out of 9 are rejected and 1/3 of hypotheses (A-5, A-6, A-8) were insisted clearly.

\section{Conclusion}

Shopping streets at local city in Japan became old and are generally declining. In this paper, we handle the area rebirth and/or regional revitalization of shopping street. We focus on Fuji city in Japan. Four big festivals are held at Fuji city. Many people visit these festivals including residents in that area. Therefore a questionnaire investigation to the residents and visitors is conducted during these periods in order to clarify residents and visitors' needs for the shopping street, and utilize them to the plan building of the area rebirth and/or regional revitalization of shopping street. Hypothesis testing was executed based on that. There is a big difference between Fuji district and Yoshiwara district. Therefore we have focused Yoshiwara district in this paper.

In the hypothesis testing, 3 out of 9 null hypotheses were rejected and 1/3 of hypotheses (A-5, A-6, A-8) were insisted clearly. Although it has a limitation that it is restricted in the number of research, we could obtain the fruitful results. To confirm the findings by utilizing the new consecutive visiting records would be the future works to be investigated.

\section{Acknowledgements}

This study was made possible through the extensive cooperation of the Fuji Chamber of Commerce and Industry, Fuji-city, Kogakuin University KINOSHITA Laboratory, KATSUMATA MARUYAMA ARCHITECTS Co., Ltd. , and others. And finally, the authors are grateful to all those who supported us for answering the questionnaire investigation.

\section{References}

Atami City. (2015). 2014 Survey of Tourist Behavior.

Doi, H. (2009). Evaluation of policies to build tourist destinations and statistical analysis. Nippon Hyoron Sha.

Ingu, S., Uemura, M., Uchida, Y., Omiya, M., Miura, T., \& Hironori, H. (2017). A study on the application of geothermal power generation to local revitalization in Obama Town, Unzen City: in consideration of futurability in Obama. Environmental Science Research, 20(1), 51-63.

Inoue, A. (2017). Changes in Local Communities Brought by Municipal Mergers: From the Viewpoint of Tourism Promotion as the Main Industry. Bulletin of the Faculty of Regional Development Studies, 2, 1-32.

Japan Tourism Agency. (2015). Research study on economic impacts of tourism in Japan 2013, p3.

Kano, M. (2011). Characteristic analysis of Atami tourists: Reconsideration based on data add and modify. Shizuoka Economic Research, 16(2), 61-78. Shizuoka University.

Kotani, A. (2017). The implementation report of the Machi-lab shutter art project. Bulletin of Wakkanai Hokusei, (17), 207-218.

Ohkubo, Y. (2017). Current status and problems in Jigenji-dori shopping area: from a consumer questionnaire. Bulletin of Local Research, 44(2), 1-15.

Retrieved from http://www.kawazu-onsen.com/eng/

Retrieved from https://www.jnto.go.jp/eng/location/rtg/pdf/pg-410.pdf\#search='Izupeninsula'

Shioya, H. (2009). Overview and application of tourism statistics: Analysis using statistical survey on overnight travels. Journal of Economic Structures, 17(1-2), 16-29. Pan Pacific Association of Input-Output Studies.

Yoshida, I. (2009). Consideration on the Characteristic of Visitors' Activity and the Research Method for Tourist Visitors in Urban Areas. 